\title{
La prensa republicana de Sevilla ante las elecciones del 12 de abril de 1931: el semanario Crítica
}

\author{
Concha Langa Nuño \\ Grupo de Investigación en Estructura, Historia y Contenidos de la Comunicación \\ Universidad de Sevilla
}

0

Análisis histórico de la victoria electoral de los republicanos-socialistas, a través del semanario político Crítica. El 9 de abril nace Crítica, declarándose por la libertad civil contra todo despotismo y en clara defensa de la República. Periódico caracterizado por su alta calidad de composición y sus grandes titulares, estaba dividido en dos parcelas: una política y otra dedicada a la cultura. Mediante el estudio de los artículos publicados en este semanario de crítica y opinión se ofrece una visión de la ciudad y de España, envueltas por la incertidumbre. Los articulistas son importantes personajes, como Antonio Núñez de Herrera, Diego Martínez Barrio o Antonio León. En opinión de la autora, Crítica se encuentra cercano al partido Republicano Radical en Sevilla. Considera que fue uno de los más fallidos intentos de organizar una cobertura de los hombres de Martínez Barrios en la capital.

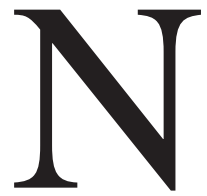

o cabe duda que la caída de la Monarquía española y la proclamación de la segunda República es uno de los momentos fascinantes del siglo XX español por las características especiales que rodearon el caso. Al mismo tiempo, tampoco cabe duda que la fuente hemerográfica ofrece un particular interés a la hora de aproximarse al pulso de la sociedad en la Edad Contemporánea. Así, si una vía para acercarse a cualquier fenómeno de esta etapa histórica es la de acotar la opinión "pública" o "publicada" a través de la información ofrecida por los periódicos teniendo en cuenta sus diferentes ideologías, si se trata de un semanario político, como es el caso de CRÍTICA, que se publicó justamente en ese momento de transición respondiendo a unos ideales, y sobre todo, a unos fines concretos, encontraremos un excelente termómetro para averiguar la temperatura de una de las variantes que intervinieron en tan complicado proceso. 
El advenimiento de la República se produjo de forma algo "anormal", tras unas elecciones municipales cuyo proceso ha sido de sobra estudiado. Baste decir que la caída de la Dictadura llevaba a un callejón sin salida por, entre otras causas, la grave crisis económica que, con sus secuelas de tensiones sociales, se proyectó sobre España. Se produjo así, un cambio en la "opinión pública", manifestado en las revueltas estudiantiles y en la ausencia de confianza de los militares ante la figura del dictador. Por estos motivo, Primo de Rivera dimitió el 28 de enero de 1930, iniciándose un periodo de transitoriedad con el gobierno del General Berenguer. Sin embargo como dice Alvarez Rey:

"El problema político en que se debatía el país permanecía inalterable, con el agravante de que la España de 1930 no era ya la de seis años atrás: la dictadura había vacunado a muchos españoles contra el miedo a la República, idea que se configura ya como una alternativa viable al caduco sistema de la Restauración que el general Berenguer piensa volver a implantar. Desaparecido Primo de Rivera, quien estaba en peligro era el propio rey. (...)lo que va a dilucidarse a partir de entonces es la continuidad o no de la institución monárquica. República o Monarquía, éstas serán las dos ideas que polarizarán y configurarán desde el primer momento a las fuerzas políticas sevillanas» 1 .

Ante eso, es lógico que las diferentes fuerzas tomaran posiciones de modo que se operó una bipolaridad política e ideológica en grado radical. Remitiéndome de nuevo al caso sevillano, por su significación y posible representatividad, la evolución de dichas fuerzas ayuda a comprender la actitud de la prensa en relación con los acontecimientos políticos y la "opinión" vertida sobre los mismos.

Sobre la capital hispalense han aparecido en los últimos años magníficos estudios que nos dan una perspectiva muy completa sobre el período ${ }^{2}$. Remitiéndonos a ellos, observamos la existencia por un lado del bloque de

\footnotetext{
ALVAREZ REY, Leandro: Sevilla durante la Dictadura de Primo de Rivera. La Unión Patriótica sevillana. 1923 1930. Diputación Provincial de Sevilla. Sevilla 1987. p.255

2 Entre ellos destacan; MACARRO, José Manuel: La Utopía Revolucionaria. Sevilla en la Segunda a República. Monte de Piedad y Caja de Ahorros de Sevilla, Sevilla,1985. TUSELL, Javier: La Crisis del Caciquismo Andaluz. (1923-1931). CUPSA, Madrid, 1985. BRAOJOS, ALVAREZ, PARIAS: Sevilla en el siglo XX (1868-1950). Universidad de Sevilla, Sevilla, 1990. Y ALVAREZ REY, Leandro: Sevilla durante la Dictadura de Primo ... Op. cit., y La derecha en la II República: Sevilla, 1931-1936. Universidad de Sevilla, Sevilla 1993.
} 
derechas o "monárquicos". Formado por numerosos grupúsculos, se hallaba muy dividido, y en estos momentos se agrupó y reagrupó formando diferentes coaliciones. Finalmente se presentó a las elecciones municipales de abril de 1931 en dos listas: la Concentración Monárquica que compusieron los conservadores de antaño y la Unión Monárquica Nacional (prolongación de la Unión Patriótica primorriverista); y la Coalición Liberal Monárquica, formada por los romanonistas, albistas y reformistas. La postura que tomaron ambos sectores monárquicos es confusa. Calificada de "plural" por Tusell y de "reduccionista" por Macarro, se ciñó a una defensa de los principios tradicionales. De cualquier modo, este no saber permanecer unidos frente a un enemigo cada vez más fuerte y la carencia de una propaganda inteligente encauzada a divulgar la importancia del momento histórico son algunas de las causas que, para Tusell, ayudan a comprender la victoria electoral de los republicano-socialistas del 12 de Abril de 1931.

En el otro lado del escenario político, figuraba el Bloque de Izquierdas, al que también se podría denominar "antimonárquico". Formado por republicanos, socialistas y algunos liberales, había difundido un Manifiesto cuyos puntos iban dirigidos a la consecución de Cortes Constituyentes, soberanía nacional y liquidación por vía jurídica de la Dictadura. En su seno había decidido mantener la independencia de cada partido. De éstos, el más fuerte era el Partido Republicano Radical, agente tiempo atrás de un importante proceso reorganizativo bajo la dirección en la capital hispalense de Diego Martínez Barrio donde tenía su plaza fuerte debido a una gran popularidad. Junto a él, los socialistas que, al contrario que en el resto del país, gozaban sólo de discreta implantación. Por su parte, los liberales terminaron abandonando el Bloque por la presencia de los socialistas, culminando de este modo el proceso de disgregación comenzado años atrás. La postura ante los comicios municipales de estas fuerzas fue más allá de lo puramente local y, así, para los socialistas «el único dilema clave en el momento que vivían era optar por la Monarquía o la República, y todo lo que fuera distraer la atención del elector de esta opción era "una desviación del camino revolucionario que sigue el proletariado español"» ${ }^{3}$. Todavía más a la izquierda de éstos, se encontraban los anarquistas, quienes carecían de una actitud política claramente definida con relación a las elecciones; y los comunistas, los cuales se presentaron en solitario pues buscaban realizar unas elecciones revolucionarias

MACARRO, J.M.:La Utopía Revolucionaria...Op. cit.,p. 103. 
en contra de una República burguesa como la pretendida, según ellos, por los socialistas.

En cuanto a la prensa, en ese momento los diarios que veían la luz en la ciudad eran: El Correo de Andalucía, El Liberal, El Noticiero Sevillano, La Unión y $A B C$. Su actitud ante las elecciones municipales de abril, y la proclamación de la República dependió de su línea editorial. Comenzando por el decano de los periódicos sevillanos, El Noticiero Sevillano, respaldado por hombres de conocida ideología liberal, su moderación le inclinó antes de las elecciones por la Concentración Monárquica, más al conocerse los resultados electorales, acató la decisión soberana del pueblo. El Correo de Andalucía "diario católico de noticias", órgano de la derecha católica sevillana, apoyó a la Concentración Monárquica, atacando a la Coalición republicano-socialista, actitud que mantuvo después, criticando la validez del advenimiento de la República. El Liberal, "diario de información general", informó bastante de la acción de los republicanos-socialistas durante la campaña electoral. Tras proclamarse la República, expresó su satisfacción esperanzada en el nuevo régimen. La Unión, "diario independiente" en este momento de transición fue el diario que más férreamente defendió los intereses monárquicos, recomendando votar a la Coalición Monárquica. Cuando se conocieron los resultados de las elecciones, el mismo día 13, publicó un artículo titulado, Monárquicos ayer; Monárquicos hoy más que ayer de su director Domingo Tejera, en el que, defendiendo más fuertemente que nunca dicho ideal. El $A B C$, diario monárquico, mantuvo una clara postura durante todo el periodo electoral en defensa de Alfonso XIII. Más aún, a pesar de sorprenderse del triunfo de las izquierdas, reafirmó sus ideales monárquicos el día 14 de abril, aunque, por respeto a la soberanía nacional, acató la República, sin renunciar a la lealtad a los principios de la monarquía alfonsina.

Como puede verse, unos diarios comprometidos ideológicamente pero dentro de un restringido abanico que incluiría la derecha y un centro moderado. Se echa en falta una prensa de partidos que incluyese las tendencias de izquierda: no existen periódicos del partido republicano radical o del socialista y muchos menos de tendencias más radicales.

Éste es el ambiente informativo en que se desenvuelve la prensa sevillana y en el que surge el semanario político y de información CRÍTICA, 
que aparece el jueves 9 de abril, justo tres días antes de las elecciones, con un primer número de cuatro páginas. El segundo lleva fecha del lunes 13 con los resultados obtenidos, más, debido a lo precipitado de los acontecimientos, se publicó el día 14 incluyendo una serie de noticias de última hora, y dos páginas centrales que bajo un inmenso, ¡Viva la República!, confirmaban la proclamación. Este número vio muy incrementado su contenido, de cuatro a catorce páginas, añadiendo nuevas secciones. El tercer y cuarto ejemplares aparecen ya en su fecha, los lunes 20 y 27, manteniendo la ampliación de espacio y secciones. El semanario, de tamaño tabloide a tres columnas, se caracterizó por su muy alta calidad de composición, usando grandes titulares, e introduciendo dibujos, caricaturas y fotografías.

En el primer número, en su contraportada, aparece el propósito del semanario:

«CRÍTICA nace, bajo la luz del sol, como una criatura fuerte y sana, a la que el libre oxígeno de la plaza pública ha de vivificar los pulmones. No lleva este niño robusto una bandera en la mano, porque su bandera es la vuestra, lectores y amigos. Ha nacido para vosotros, los que pensáis con el propio cerebro y no teméis el resplandor de las auroras. Es ingenuo y libre; esto es todo. A veces, levantará entre las manos su propia hoja de papel, como un espejo. En él se reproducirá la vida, la vida que pasa y la que quiere llegar. Este espejo crítico deformará, a veces, la imagen; pero será para tornarla más visible. Esta es su función de glosador, de comentarista. No adulará a nadie, ni siquiera al pueblo. Su rótulo es la verdad, con las limitaciones subjetivas que siempre tiene la verdad, que no es tan orgulloso que se crea infalible. No tiene partido, en cuanto un partido es frontera y delimitación Pero tiene un gran partido: el de la libertad civil contra todo despotismo, amanezca por Levante o se obscurezca por Occidente». Esta línea la defendió de principio a fin.

En el aspecto formal, el semanario se organizó en distintas secciones, claramente diferenciadas por una cuidada tipografía, que se van incrementando al avanzar los números. Como es lógico, los editoriales, fundamentales para el conocimiento de la posición sociopolítica del mismo, aparecen en primera página. En la segunda, encontramos en todos los números de CRÍTICA, 
Sonrisas y Comentarios, un apartado satírico de marcado carácter político y social. Realmente es éste su plato fuerte con diferentes artículos de pequeña extensión, algunos firmados. Las demás secciones van a variar su emplazamiento a excepción de Impactos, muy destacada tipográficamente, que ocupa la contraportada, con una serie de pequeños "flashes", de elevadísimo tono satírico, sobre diferentes aspectos de la vida política y ciudadana. A partir del segundo número, en el que aparece en la tercera, la sección El Panorama Nacional, incluye artículos de opinión, en su mayoría sin firma, y noticias acompañadas de un breve comentario, que pueden ocupar más de tres páginas. El cuarto apartado es el denominado La Vida en la Ciudad. De iguales características que el anterior, se ofrece como su continuación, a excepción del último número en el que se encuentra antes. Tras ellas, en el número tres y de modo único se incluye un apartado sobre La Actualidad Mundial, de información internacional.

Otras secciones que se mueven en el semanario son, en todos los números la dedicada a Arte y Literatura; y, a partir del tercero, una sobre Cine y Teatro, y otra sobre Deportes. La primera, por su continuidad muestra la relevancia que se le dio al aspecto cultural. Estaba compuesta por dos partes: la artística, y la de crítica literaria. Con respecto la primera, Núñez de Herrera firmó un texto en todos los ejemplares, a excepción del tercero. Junto a esos, aparecen dos de Manuel Villalobos Díaz sobre la crítica artística de la exposición de Bellas Artes. Una segunda parte bajo el epígrafe "Los Libros", hace juicio literario a libros de muy diversa índole, en su mayoría ensayos publicados por el C.I.A.P. -Consorcio Iberoamericano de Publicaciones- de Madrid. Las otras dos, Cine y Teatro, y Deportes -con noticias procedentes de la agencia "Noti Sport"-, muestran el intento de abarcar la mayor cantidad de información por semanario conforme parecía consolidarse.

Por tanto, tras una primera mirada, un semanario dividido en dos claras parcelas, una primera parcela dedicada a la política, completada por secciones culturales.

Como ha podido observarse, este semanario se presentó como expresión crítica y de opinión. Pero, ¿cuáles fueron los blancos de esta CRÍTICA? Básicamente los temas tratados los redujo a los de tremenda actualidad en ese periodo, y por ello, los relacionados con los cambios políticos acaecidos 
en el país y en Sevilla. Eso sí, dada la velocidad histórica de los acontecimientos, cada número reflejó las mutaciones habidas en la perspectiva de ese instante. De acuerdo con esto, el primer número, editado en el final de un gobierno monárquico, tres días antes de las primeras votaciones habidas en España en siete años, dedica su editorial A los electores que van a votar el domingo. En él, el semanario manifiesta ya su ideología, pues, tras resaltar la importancia histórica de tales comicios al suponer un «recuento de votos contra la Monarquía y cuanto ella representa y defiende», pide al elector su repulsa contra «los que llevaron a España al caos económico, político, social y jurídico presente», y descalifica a todos los que habían representado a la Dictadura. Frente a éstos pide que se preste atención y apoyo «a los que quieren acabar con la humillación, la opresión y la ruina del país y los habitantes... a los que representan, no la defensa de una dinastía extranjera, sino a la libertad y la felicidad de los españoles». Por tanto, no es extraño que el editorial termine con un «Votad la candidatura Republicano-Socialista ${ }^{4}$. A renglón seguido, el apartado Sonrisas y Comentarios, en idéntica orientación incluyó tres pequeños artículos. De ellos destaca el titulado Cortes Reconstituyentes en razón a la mordacidad con que ataca al Gobierno, todavía monárquico, y a la posible reunión de Cortes Constituyentes. Hace en tono irónico un juego de palabras entre Cortes Constituyentes y el «tónico reconstituyente» que el Gobierno necesitaría para, a su juicio, poder continuar; un «reconstituyente» hecho de la «carne del pueblo», recomendando a los «pastores» tengan cuidado de los «lobos de la política». También ironiza mordazmente Antonio Núñez de Herrera en su artículo, Otoño en Primavera acerca de cómo las «hojas amarillas» de las proclamas monárquicas tiradas al suelo, daban un aspecto otoñal a las calles sevillanas en plena primavera. La página se completa con eslóganes propagandísticos, dirigidos a considerar el carácter político y no municipal de las elecciones, la necesidad de la exigencia de un sufragio libre por parte del pueblo, y cómo la coalición republicano-socialista persigue este propósito. El semanario concluye con unos Impactos en los que son elegidos como blancos los personajes políticos de la Dictadura; Marqués de Torrenueva; Pedro Caravaca; Díaz Molero; Cruz Conde; La Cierva; el general Cavalcanti; el general Saro..., y la Exposición Iberoamericana por su coste económico para los sevillanos, y su falta de utilidad. En la columna central es donde se incluye el propósito del semanario citado párrafos atrás.

4 CRÍTICA 9-IV-1931, p. 1. 
El segundo número -según se dijo- es el fechado el lunes 13, pero publicado el mismo día 14 . O sea, su editorial se escribe en el momento en que se acaban de celebrar las elecciones y se conoce el triunfo de las candidaturas de izquierdas, pero aún no se ha proclamado la República. Es el único que aparece firmado y lo es por Mario Jocard. Lleva por título Poder social y Poder estatal. En primera, a dos columnas una caricatura titulada Alegoría Monárquica -muestra una calavera dentro de su ataúd-, con una cuña informativa debajo en la que, tras congratularse por el triunfo de las candidaturas republicanas, mostrando su fe en que la República sea la salud y paz futura para España, se anuncia amplia información electoral en las páginas interiores. Tras ello se inicia el editorial, en él que Jocard habla de la diferencia entre la España real y la oficial. Comenzaba afirmando la existencia en España de un divorcio entre la voluntad nacional y lo que el Estado traducía. El causante había sido para él la Restauración pues fue un régimen de ficciones en el que se llegó a legislar para sí en contra de los incluso llamados amigos, conviviendo legislaciones y modos quasi feudales con una legislación social tan avanzada que aún su recuerdo hacía temblar a la pequeña burguesía. Jocard concluía afirmando que «las dictaduras son siempre de clase. La rusa es proletaria y la italiana burguesa. Para que no exista superposición despótica de ninguna clase social contra las otras no hay más fórmula de convivencia humana que la democracia» 5 Esto sería lo que pretenderían ahora en España muchos hombres llamados intelectuales. Jocard ponía su esperanza en que España aprenda a ser una democracia y olvide pasadas costumbres y errores.

Tras dos artículos aparecidos en la sección Sonrisas y Comentarios sobre cómo la elocuencia del político profesional sirve para captar a un rico indiano como concejal a cambio de su dinero-, y una caricatura del panorama electoral existente -compara la Candidatura Monárquica Liberal con tres cadáveres anónimos solitarios sin nadie que los llore abandonados en la calle-, la información nacional ocupa, en este número del 13 de abril, cinco páginas. Con un completo seguimiento a los resultados electorales en el país y cuatro artículos de opinión. Antonio Núñez de Herrera en El estilo en la política, defiende que «el mal fundamental de la política española es su estilo. (...) tiene tantos estilos como políticos. El estilo anula el ideario, la pauta y el programa. Como el estilo es el hombre, la política, por traslación es el

\footnotetext{
CRÍTICA 13-IV-1931, p. 1.
} 
hombre también». Así pues, y a su juicio este personalismo caudillista sería el mal principal del sistema político español, y sería también el responsable del derrumbe monárquico. Núñez de Herrera llega a decir: «La política española ha sido en todo tiempo un estilo y una furrielería» ${ }^{6}$. En la cuarta página se reproduce parte del manifiesto de Los intelectuales republicanos, Ortega y Gasset, Pérez de Ayala y Marañón, especialmente los párrafos que atacan el alejamiento de la Monarquía española respecto del pueblo, y muestran esperanza hacia el nuevo estado republicano. La quinta plana estaba ocupada por un extenso artículo de José de Montes, La agonía del régimen. En él planteaba la enfermedad de origen del régimen de la Restauración, experimento que se mantuvo por la falta de interés político del pueblo español debido a la profunda división entre el Estado y el pueblo. La clave era la imposibilidad de democratización de la Monarquía; por ello aseveraba que: «es imprescindible destruirla y levantar un Estado nuevo que sea fruto de estas esperanzas que hoy alientan en el corazón de los españoles» ${ }^{7}$.La sección se completaba con diversas cuñas en negrita, en una, un mensaje $A$ las clases conservadoras - firmado con las iniciales R.M.- declaraba que los verdaderos hombres de orden y auténticos conservadores eran los republicanos por actuar en conciencia con lo que deseaba la mayoría y por requerir la restauración del «Derecho violado»

Los resultados electorales sevillanos aparecen en la sección La vida de la ciudad, con notas sobre los incidentes ocurridos o información del conjunto de sufragios en los distritos afirmando que «Sevilla vuelve a encontrarse a sí misma». Es aquí donde introduce unas Opiniones de personalidades políticas; de Ramón Carande, (catedrático y de la agrupación al servicio de la República); Hermenegildo Casas, (jefe de la agrupación socialista sevillana); Ramón González-Sicilia (vicepresidente del Partido Republicano local); Moreno Gallego (presidente de la Juventud Republicana); y González Taltabull (secretario del partido Republicano Autónomo de Sevi1la), quienes muestran su entusiasmo por los resultados. Como telón de fondo y bajo la viñeta de Impactos, unas víctimas: la Unión Patriótica y, sobre todo, la Unión Monárquica, a la cual entierra sin piedad. También un aviso para que no se venda España, en forma de créditos, a Estados Unidos, como las demás repúblicas sudamericanas. Por último, CRÍTICA ofrece su amistad a

\footnotetext{
CRÍTICA del 13 de abril de 1931, p. 3.

CRÍTICA del 13 de abril de 1931, p. 5.
} 
los productores: «Ni las extorsiones de la Hacienda, ni los descuidos de los gobiernos, ni las impalpables tendencias, de carácter ideológicos que cunden por ahí, y que, en definitiva, se traducen en nuevas persecuciones contra los productores, encontrarán en nosotros cómplices silenciosos sino severos fiscales» 8 .

El tercer número ve la luz el lunes 20 de abril, ya inaugurada la República; es decir entre el entusiasmo y la preocupación de una España llena de incertidumbres ante la necesidad de desprenderse del pasado y emprender un futuro mejor. Ello se puede observar en los dos editoriales que aparecen en la portada. El primero, con el título, Deberes de ciudadanía, hace una apología de la democracia, a la que avala incluso con citas de doctores evangélicos, y un ataque a todas las formas dictatoriales: «todas las dictaduras de minorías, sean favorables o adversas a los obreros, son un crimen, un gran crimen histórico». Unas ideas que extrae del siguiente principio populista: «la fuerza no crea el derecho (...) El orden verdadero, es decir, el fundado en la voluntad general, es sagrado». Así, el semanario recuerda los deberes implícitos en los derechos y más en el momento en que se acaban de conseguir; deberes de ciudadanía, en suma, que formalizan su compromiso como medio de comunicación. El segundo, bajo el enunciado, Nuestro caballeroso monarca, es utilizado como réplica a las amenazas hechas sobre una posible vuelta del rey al poder. De ahí su fuerte crítica a la figura de Don Alfonso de Borbón y su «última faena» en términos como estos: «Pero la masculinidad es equivalente a dignidad y hay que reconocer que el que fue rey de España ha rematado su suerte dejándose en España la dignidad real y la ordinaria» 9 . Este anhelo de salir de la transitoriedad marca las diferentes secciones del semanario. En esa línea, Sonrisas y Comentarios, después de satirizar la historia del típico medrador que hacía carrera dentro de los viejos círculos oligárquicos y que de repente, se pasa al bando republicano, reprocha La marcha de los responsables por la blandura del Gobierno al haber dejado ir a «los más altos responsables de los últimos años de ignomia» gentes para las que pedía la extradición pues, «amasaron una fortuna a fuerza de grandes estafas y vergonzosos corretajes» 10 .

Dentro del Panorama Nacional, CRÍTICA muestra su empeño por fundamentar teóricamente el nuevo régimen. Núñez de Herrera en, Teoremas

\footnotetext{
CRÍTICA del 13 de abril de 1931. p. 14.

9 CRÍTICA, 22-IV-1931, p. 1.

${ }^{10}$ CRÍTICA del 20-IV-1931, p. 2.
} 
de la República lo hace recorriendo los diversos momentos históricos de la política española. Desde las Monarquías de Antiguo Régimen a la dictadura de Primo de Rivera, no había habido en España una verdadera democracia, incluyendo los períodos constitucionales, «una tiranía al cuadrado servida por gente aldeana y apetente». Concluye afirmando que al faltarle fuerzas al monarca y valor a los monárquicos se situaron «frente a frente, el rey y el pueblo; la tiranía y los ciudadanos; la dinastía colonizadora y la nación; venció el pueblo» ${ }^{11}$. El artículo termina con una Aclaración muy al estilo del pensamiento burgués diferenciando a este pueblo triunfador de la «plebe» que se «desmandó» el día quince en la calle.

La sección continúa con pequeños apartados compuestos de cuñas a modo de mensajes destinados a la clases media y al pueblo en general. Destacarían los que fustigan a esas clases medias por no acreditarse a fondo como demócratas o por despreocuparse de la política, y los que invocan un sentimiento colectivo para el mejor funcionamiento de la democracia. También se ataca al régimen anterior en la figura de la Exposición Iberoamericana, y en los famosos arbitrios pagados por los sevillanos para sufragarla. Ya en la quinta plana hay un artículo de colaboración firmado por Feijoó y Torres en Barcelona el 16 de abril sobre El error Maciá. En él Feijoó, que partía de una posición radicalsocialista y por ello federalista, sostenía que la desmembración de la República española en pequeñas nacionalidades era un groso error; rebatía la proclamación de la República catalana desde la lógica electoral ya que entendía que en el referéndum del día 12 no sólo no ganaron los separatistas, sino que únicamente a las Cortes correspondía la potestad para tal proclamación; por tanto, Maciá debía haber esperado. Con todo, la opinión de Feijoó se completa con un editorial acerca de la desaparición del problema por la decisión de Maciá de respetar el Pacto de San Sebastián, ante lo cual se congratulaban asintiendo: «la República tiene, sin duda, el favor de Dios, porque los asuntos más arduos se resuelven en horas» ${ }^{12}$. La sección se cierra con un pequeño artículo, de marcado cariz literario, que propugna el optimismo para la «nueva edad» que se está viviendo en el mundo.

La vida de la ciudad refleja la constitución del nuevo Ayuntamiento hispalense, relatando el acto social y político al efecto. Tras aquel, reproduce un telegrama del Ministro de Comunicaciones, Martínez Barrio agradecien-

${ }^{11}$ CRÍTICA, 20- IV-1931, pp. 3-4.
${ }^{12}$ CRÍTICA , 20-IV-1931, p. 5. 
do un saludo del Ayuntamiento, y entre chistes satíricos antimonárquicos, escritos y caricaturas pro-republicanas, inserta un Saludo al Gobernador: «CRÍTICA, que nació ha días bajo la amenaza del Código de la Dictadura, con vida asfixiada, hoy respira el libre oxígeno de la República, se complace en saludar fraternal y respetuosamente al gobernador republicano»13. La octava página acoge de modo único la sección La Actualidad Mundial, con opiniones sobre la crisis de Rumania, -a causa de los afanes personalistas del rey Carol-, y la Política Inglesa, -por la tensión del gobierno de coalición entre laboristas y liberales-.

Tras las secciones de Arte y Literatura; Cine y Teatro; y Deportes, este tercer número se cierra con los Impactos de una contraportada en la que piden responsabilidades a las autoridades del anterior régimen, como Cruz Conde, y solicita la marcha de los antiguos políticos, como Guadalhorce o los Ibarra. También censura a El Liberal por incluir unas declaraciones comunistas, recordándole al diario de Laguillo que no se puede publicar «cualquier cosa», y que existe una frontera entre ellos, los republicanos, y el «depotismo asiático». O sea, dando a entender que la libertad de prensa tiene su límite en la extrema izquierda marxista.

El último ejemplar de CRÍTICA presenta en primera plana dos viñetas en las que aparecen, a un lado, una manifestación jubilosa a favor de la República y, en el otro, la figura alegórica de la misma amenazada por un fraile quien intenta apuñalarla por la espalda, con el pie: «Realidad..» Tras ambas el editorial bajo el título Una nota del Sr. Alcalde. En él se habla del verdadero y desastroso estado de la hacienda municipal tras los ayuntamientos de la Dictadura. El escrito pide que se tomen medidas contra los culpables de tales «líos gordos» y por ello: «ahora lo que hace falta es que se haga con todos, con los últimos y los penúltimos, una sola redada y que sean entregados a los tribunales competentes» ${ }^{14}$. En especial, se mostraba duro con el Banco de Crédito Local por cobrar intereses de un préstamo no dado, y con Pedro Caravaca por haber pretendido demostrar un superhabit inexistente en las arcas municipales. Todo esto hace que el editorial termine con una irónica crítica la Unión Patriótica a quien se acusa de adulterar «hasta las matemáticas».

La sección Sonrisas y Comentarios está compuesta este último número por tres artículos. En el primero se hace una dura crítica a la figura del

${ }_{13}$ CRÍTICA, 20-IV-1931, p. 7.
${ }^{14}$ CRÍTICA, 27-IV-1931, p. 1. 
Dr. Albiñana y sus Legionario de España. El segundo es un poema que, con el título El Primado y la primada, descalifica al Cardenal Segura por su actitud respecto a la República. Su tema es el siguiente.

Quién os viera Cardenal más metido en vuestra casa, entre alfombras y tapices, entre rezos y sotanas. Ay, quién os viera Arzobispo primados de las Españas, recapacitando en que ya se acabó la primada. Quién os viera, Cardenal, metido a la cura de almas y no a negocios políticos; propios de gente pagana. Señor Cardenal Segura: ya hay república en España. Si nos va tan bien con ella, ¿por qué vos con esa saña, pedís que Dios la castigue, que su maldición le caiga? ¿Por qué desde los altares pedís a Dios su desgracia si gracias a Dios le vino tan divinamente a España? Señor Cardenal Segura: no maldigáis la muchacha, que para suerte de ustedes nació demasiado santa. Curáos más de lo divino que de las cosas humanas, mirad que la Virgen fue al fin una proletaria y Jesús un socialista mártir como los de Jaca. Recordad que fueron reyes quienes a Jesús mataran. No maldigáis la República, señor primado de España, mirad que os estáis metiendo en casullas de once varas, y es la República ahora quien paga vuestra soldada»15 .

El texto es tan suficientemente esclarecedor de las ideas que merecía la posición del Cardenal Segura a los hombres de CRÍTICA que no necesita comentario. Eso sí, sobresale su sentido propagandístico en algunos versos resaltados en cursiva, referentes a diversos temas: cómo la pobreza evangélica estaría más cerca de las ideas sociales que defiende la República; un recuerdo a los llamados "mártires de Jaca"; y el ataque a la Monarquía en la figura de quienes mataron a Jesús. Nótese pues que no se hace en ningún momento un ataque a la religión, sino a las formas efectuadas por los representantes eclesiásticos. 
Después de firmar Núñez de Herrera La guardia civil y los parados, en el que se comenta como el cuerpo de la benemérita por fin puede hacer gala de su nombre pues, con la llegada de la República, ya no ha de obedecer órdenes contra los obreros, la sección se completa con otra cuña propagandística que, por su claro mensaje, merece ser reproducida: «Los obreros que eran recibidos a palos cuando pedían pan y trabajo, o, simplemente justicia, deben saber ahora esperar de grado puesto que antes esperaron a la fuerza. Cualquiera actitud contra el Ayuntamiento y la República irá en contra del pueblo mismo en sus organismos representantes» ${ }^{16}$. Sin duda, le interesaba esta advertencia a la clase obrera para su contención y comedimiento, en la medida de los logros de una República "burguesa".

En tercera La Vida en la Ciudad, continúa esa línea. Así, un artículo dedicado a los obreros en paro que acuden al Ayuntamiento a apuntarse en las listas de parados, denuncia como las derechas, en «fea maniobra demagógica», les utilizan para hablar de una crisis que ya existía. Por su parte, el concejal republicano Manuel León Trejo, firma un comentario satírico sobre una información de $A B C$ en el que, sarcásticamente, emite un gesto de comprensión hacia los que aún no aceptaban la proclamación de la República.

El Panorama Nacional de este último número, sigue siendo una de las secciones más jugosas, con un grupo de artículos de opinión de media extensión sin firma. En ellos se pueden observar las preocupaciones del medio por la República recién estrenada. Así, el semanario pide que no se vuelva a usar la legislación por decretos; condena al general Martínez y Anido; solicita que Capital y trabajo no sigan caminando por separado para que así, «en una misma lucha», se pueda conseguir un futuro mejor; requiere que, para la correcta administración de los problemas de España, el Gobierno no debería ser provisional -«Este Gobierno no puede ser provisional. Tiene muchos fines que rematar y muchas ocupaciones que cumplir, Puesto que acabó con las partidas que merodeaban el país, es necesario que no acaben con él los partidos. Que el pueblo le sepa defender de los partidos. Con la monarquía ha debido terminar, por ahora, el turno y el volteo de los partidos en el Gobierno de la nación» ${ }^{17}$.-; vuelve a mostrarse preocupado por $E l$ federalismo y la cuestión catalana remitiendo al punto de vista que apuntara

\footnotetext{
${ }^{16}$ CRÍTICA, 27-IV-1931, p.2

17 Ibídem, p. 6
} 
Feijoó, Cataluña puede ser una región autónoma dentro de la federación española, pero con el total consenso de los españoles y de la Asamblea Constituyente y soberana, no por un condescendiente pacto del ambos gobiernos; reclama justicia para los mártires de Jaca; y, continuando con la crítica al fenecido sistema monárquico, exige con un artículo denominado Exortaciones, que se respete al Gobierno y se ayude «no sólo a reprimir los desmanes, sino también a la gigantesca y complicada tarea de reconstruir la nación y la ciudadanía, sobre el montón de ruinas morales y materiales que nos han dejado toda una etapa de tiranías e incomprensiones ${ }^{18}$. Esta sección se completa con una última hora sobre la constitución de la Diputación provincial de Sevilla, y un extracto de la Historia de la Civilización Ibérica llamado La España contemporánea; concretamente sentencia: «España siempre fue una democracia. Lo fue en su estado de tribu; lo fue bajo el régimen municipal romano. La invasión de las instituciones aristocráticas germanas no pudo destruir la anterior constitución de España ni enraizar en ella el régimen de herencia y de casta, como lo hizo en el resto de Europa. Este hecho social-histórico, amalgamado con el carácter de la raza, con la nobleza, el orgullo y la independencia personal, hizo de la Península una democracia ya militar, ya eclesiástica; ora monárquica, ora oligárquicamente gobernada. El fondo, como las rocas ígneas, permanecía inmutable; lo demás eran accidentes» ${ }^{19}$. En definitiva, un apasionado alegato de la democracia de inspiración liberal.

Para finalizar, Impactos denuncia el «camaleonismo» de los políticos del antiguo sistema; pide responsabilidades para los responsables del antiguo Ayuntamiento; y avisa de la continuación del «caciquismo» en la creación de comités izquierdistas en determinados pueblos dominados todavía por los antiguos «señores». En este último número aparece un pequeño recuadro muy espectacular con el siguiente mensaje: «El Gobierno y el ayuntamiento laboran por la solución de la crisis del trabajo con toda actividad./ Los obreros han de pensar solo en que el municipio se ha encontrado con las arcas vacías de dinero y con los presupuestos llenos de débitos y líos./ Hay que aguardar a que los recursos se arbitren y los embrollos se desmadejen» 20 .

Hasta aquí la descripción del semanario y sus contenidos.

\footnotetext{
18 Ibídem, p.7.

19 Ibídem, p.6.

${ }^{20}$ Ibídem, p.12.
} 
Después de esta detenida y densa exposición sobre CRÍTICA, caben ciertas observaciones puntuales:

A. La notoria presencia de los trascendentales momentos que contextualizan el semanario. Aquí, destacar la importancia ya no sólo del momento general sino del particular en que aparece cada número. Ello se puede observar desde el hecho de que, viendo la luz tres días antes de las elecciones del 12 de abril, se caracteriza por su claro propósito electoral en beneficio de la coalición republicano-socialista, con un ataque a la candidatura monárquica; un segundo que, escrito tras las elecciones y publicado después de la proclamación de la República, muestra su alegría por el triunfo republicano-socialista, alegría que se desborda al conocerse la proclamación republicana; y finalmente un tercer y cuarto ejemplares donde muestra, conseguido el triunfo deseado, un interés por dar fin con todos los restos del anterior sistema político y, sobre todo, la búsqueda de amplio apoyo social, desde la burguesía al proletariado, para la construcción de la República.

B. Una temática mayoritariamente política, o totalmente si exceptuamos las secciones dedicadas a arte, literatura y deportes. Podría dividirse en dos bloques. El primero, al que denominaremos artículos antidinásticos, ataca abiertamente al anterior régimen. Los ataques están destinados a demostrar tanto la incapacidad política, que había llevado al país al desastre, como la ineptitud de sus representantes, desde la figura del monarca hasta la de los viejos caciques. El segundo bloque sería el dedicado a lo prorrepublicano. Estaría compuesto por: la propaganda republicano-socialista para las elecciones; una apología de la democracia como único sistema válido; la continua llamada a la ciudadanía para conseguir una ayuda al nuevo sistema; un intento de concienciación a la pequeña burguesía y de los obreros de las excelencias republicanas, al mismo tiempo que se pide su paciencia; y finalmente, la total afirmación de un futuro dorado para el país con la República.

C. La autoría de los artículos que se debe a importantes personajes de la vida política sevillana como Antonio Núñez de Herrera, editor del semanario con toda seguridad, y hombre de confianza de Diego Martínez Barrio en Sevilla; o Antonio León Trejo, elegido síndico del Ayuntamiento por el partido republicano en las elecciones del doce de abril. Hombres que dentro del mundo político sevillano, estaban relacionados con la coalición republicano-socialista.

Por tanto, para concluir, tenemos un semanario más político que de información y que, autodenominado apartidista, actúa como órgano de pro- 
paganda prorrepublicano en un periodo electoral en el cual se muestra muy cercano a los intereses de la coalición republicanosocialista. Sin embargo, una lectura más detenida me inclina a opinar que el semanario se encuentra más cercano a los intereses del partido Republicano Radical en Sevilla, y ello en razón a que, de un lado, los nombres que aparecen son los de los hombres de Martínez Barrio en la ciudad, y de otro el que las ideas insertadas no responderían tanto a un pensamiento socialista como a unos mensajes proburgueses de ayuda a las clases industriales y comerciales. Esto último respondería a la procedencia burguesa de este grupo republicano.

Por todo ello, y por su corta duración, entiendo que este semanario fue uno más de los fallidos intentos de organizar una cobertura propagandística de los hombres de Martínez Barrio en Sevilla. En este sentido, CRÍTICA sería el proyecto de un órgano de propaganda en pleno periodo electoral, del mismo modo que se volvió a intentar en las primeras elecciones republicanas del 28 de junio con el "diario republicano de Andalucía" EL PUEBLO, del que fue director Antonio Núñez de Herrera. De este sólo existen doce ejemplares, de los cuales el primero data del mismo día 28 de junio de 1931 para volver a ver la luz, -año I, núm. I- el 8 de julio del mismo año. Martínez Barrio pues, no llegó a conseguir su propósito, en todo el periodo republicano, de organizar un órgano periodístico de propaganda en Sevilla, pese al gran apoyo electoral de que gozaban el ella ${ }^{21}$.

\footnotetext{
${ }^{21}$ BRAOJOS GARRIDO,A: “El regionalismo autonomista andaluz en la prensa sevillana (1900-1936), En"
} Nacionalismo y Regionalismo”. Córdoba 1986. p. 101. 